\title{
MAGNET APPLIED AT TRUCK AND BUSSES REAR AXLE HOUSING TO AVOID FIRST REPLACEMENT OIL AND INCREASE THE OIL CHANGE INTERVAL POSSIBILITY
}

\author{
Sergio Roberto Amaral ${ }^{1}$, Ricardo Alexandre Sassa ${ }^{2}$, Thayane Aparecida Silva ${ }^{3}$, Luiz \\ Antonio de Oliveira Doria ${ }^{4}$, Egidio Correia ${ }^{5}$, Edison Lopes ${ }^{6}$ \\ ${ }^{1}$ MAN Latin America \\ ${ }^{2}$ MAN Latin America \\ ${ }^{3}$ MAN Latin America \\ ${ }^{4}$ Racing Automotive \\ ${ }^{5}$ Meritor do Brasil \\ ${ }^{6}$ Meritor do Brasil \\ sergio.amaral@volkswagen.com.br, ricardo.sassa@volkswagen.com.br, \\ thayaneaparecida.silva@ volkswagen.com.br, extern.luiz.doria@ volkswgen.com.br, \\ egidio.correia@meritor.com, edison.lopes@meritor.com
}

\begin{abstract}
The truck and busses rear axle production process characteristics does not remove all impurities in parts per million (PPM) of metallic and non metallic materials, than as necessary a premature oil change knower "first replacement oil". This kind of service occurs at five thousand kilometers in average to assure the internal components life (gear assy, retainers and bearings). Evaluating the material properties and rear axle functionalities characteristics were defined to fixing some magnets inside the rear axle housing separated according to minimum distance specification each other. The main idea is attract the metallic particles in oil at rear axle to the magnets (ferromagnetic properties) and also non metallic particles by mechanical friction created by oil movement around gear assy. Considering the impurities volume found out at samples universe at durability tests done are in PPM, the magnets dimension were defined to all rear axle life prediction. Oil samples were evaluated during durability test according to truck and busses maker, rear axle supplier and oil laboratory specialist definition. Up to now, the results show the materials reduction at suspension particles at oil and physical chemical characterizes oil stability after one hundred twenty five thousand kilometers $(125.000 \mathrm{~km})$. Were considered, based on the results, the magnets assembled at rear axle housing avoid the first replacement oil. Evaluating all analysis results were defined to increase one hundred kilometers (100.000) and keep the oil analysis. Tear down will be done, according to test schedule, after two hundred twenty five thousand kilometers $(225.000 \mathrm{~km})$ to evaluate the gear assy regarding a wear and carbon case reduction, retainers condition, bearings and lubricant oil condition to confirm all rear axle components and lubricant oil life prediction and also analyze the new rear axle oil change interval possibility.
\end{abstract}




\section{INTRODUCTION}

Nowadays the Truck and Busses makers normally are the responsible to pay the first replacement oil regarding to hand work according to owner's manual. Basically the current rear axle makers cleaning process does not remove all PPM particles and then the first replacement oil must be done to assure the rear axle life. The magnets applied provide some benefits for customers, Truck and Busses makers and environmental. The possibility to avoid the discharge oil not properly, reduces the oil lubricant cost paid by customer and also reduces the makers maintenance cost is the best situation for all. The definition about new oil change interval is under evaluation, however the results show no data variation after one hundred twenty five thousand kilometers $(125.000 \mathrm{~km})$.

\section{REAR AXLE AND LUBRICATION - GENERAL INFORMATION}

The rear axle is a mechanical gear assy with extreme importance for safety vehicle stability, torque transfer from engine to wheel, reduce the drag and tire premature wear. The lubrication as an essential item to keep the differential at good work condition, reducing wear friction and also temperature parts replacement. The modern's automotive lubricants are made with basic oils made by mineral, semi synthetic and synthetic bases. The lubricant bases are selected according to the film protection at mobile parts to resists mechanical shocks, temperature variation that can be change the oil properties and prevent the oxidation. The oil change interval as defined according to application and oil analysis did during durability tests. The Truck and Busses makers are the responsible to define the interval and describe the interval at owner's manual.

\begin{tabular}{|l|}
\hline Maintenance Plan \\
\hline Preventive Maintenence Plan follow: \\
\hline 1. Delivery Review \\
\hline Made by dealer before vehicle delivery \\
\hline 2. Daily Operation \\
\hline The operations must be checked daily by vehicle's owner before start running. \\
\hline 3. Weekly Operation \\
\hline Must be checked by vehicle's owner. \\
\hline 4. First Replacemanet Oil \\
\hline Executed by dealer - between $1000 \sim 5000 \mathrm{~km}$. \\
\hline
\end{tabular}

Table 1. Truck and Busses Maintenance Plan

\section{PROJECT DESCRIPTION}

Evaluating the durability test vehicles oil analysis already tested we could confirm metallic and non-metallic particles in PPM over than maximum limits defined by maker and viscosity according to SAEJ306. The high volume found out as a consequence of manufacturing process (stamping, casting, machine and etc.). This kind of materials could cause wear at gears through friction. To avoid the differential premature wear was defined to do the first replacement oil. This process removes the materials in excess and then keeps the differential life predicted for the vehicle application. Considering the maintenance plan showed at table 1, the first replacement oil are made by $80.65 \%$ of all Truck and Busses maker according to benchmarking done. The others $19.35 \%$ decide to use filter inside of axle housing, introduce magnets with synthetic oil bases or reduce the oil change interval. The strategies used by makers are defined according to his engineering application knowledge and marketing requirements. The first replacement oil normally are done at dealers, however some of then use the gas station for oil 
replacement. Unfortunately this kind of practice sometimes causes an environmental problem because only $15 \%$ return to oil re-refin industries, according to Petroquimica Sul Survey on 2008. The table 2 shows the production volume previewed for 2012 and the oil volume replaced in average during first replacement oil.

\begin{tabular}{|c|c|c|c|}
\hline \multicolumn{4}{|c|}{2012 Sales Volume X First Replacement Oil } \\
\hline Makers & $\begin{array}{c}\text { Truck Market } \geq 5 \\
\text { Ton (Unit) }\end{array}$ & $\begin{array}{l}\text { Bus Market } \\
\text { (Unit) }\end{array}$ & $\begin{array}{l}\text { Oil volume (L) } \\
\text { estimated }\end{array}$ \\
\hline$M A N / V W$ & \multirow{10}{*}{175.838} & \multirow{10}{*}{40513} & \multirow{10}{*}{1.744 .870} \\
\hline MBB & & & \\
\hline FORD & & & \\
\hline SCANIA & & & \\
\hline VOLVO & & & \\
\hline IVECO & & & \\
\hline AGRALE & & & \\
\hline INTERNATIONAL & & & \\
\hline SINOTRUCK & & & \\
\hline OTHERS & & & \\
\hline
\end{tabular}

Table 2. Autodata Magazine Dec. 2012 Annual sales volume preview.

Truck and Busses makers normally pay the hand work, but the customer as a responsible to pay the oil. To avoid the first replacement oil and also reduce the high cost paid by makers was discussed with rear axle maker to assemble some magnets at rear axle housing in order to attract the metallic particles by magnetics characteristics and no-metallic particles by mechanical friction.

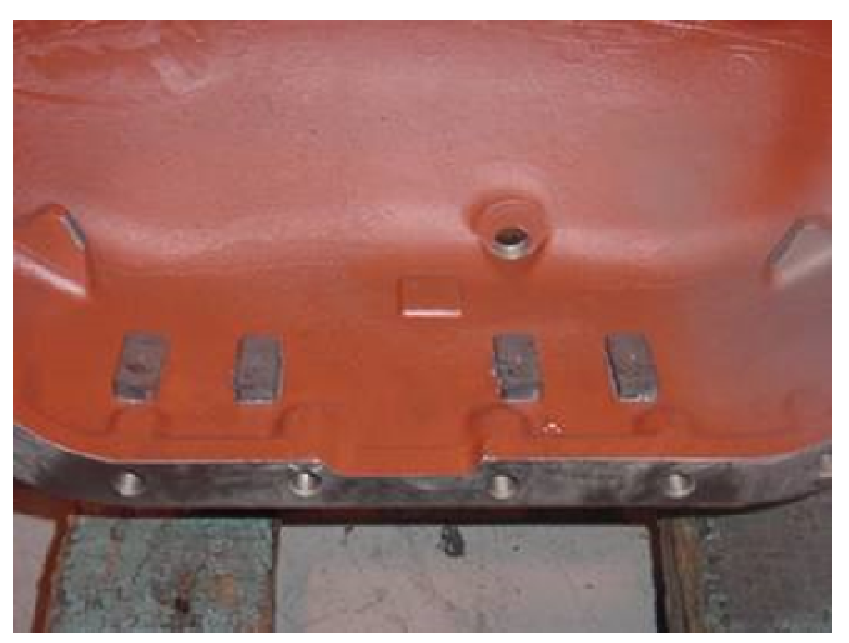

Picture 1. Magnets assembled at Rear Axle Housing (source: Meritor do Brasil)

The magnets showed at picture 1 have ferromagnetic properties to attract and repel magnetic substances. 


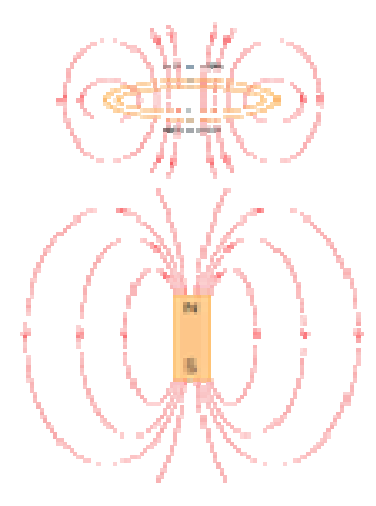

Picture 2. Magnetic field lines of forces around a current loop and a bar magnetic i.e.[1].

Several of modern equipment and jigs using a magnetic materials such as generators, electric transformers, electric engines, radios, TV's, phones and computers. When work at high temperature, the magnet lost his properties caused by disorder at his particles, called Curie temperature. Iron lost his properties at around $770^{\circ} \mathrm{C}$.

\section{VALIDATION TEST}

The vehicle defined to test the proposal was heavy duty truck 6X4 (tractor) at highway durability test with $125.000 \mathrm{~km}$ at maximum load (63 tons). The main objective was evaluating the oil and vehicle without first replacement oil. Were defined oil analysis volume and mileage intervals to collect and send to laboratory for analysis according to SAE J306 Standard. (see table 3). Oil specification: API GL5 85W140, mineral base.

\begin{tabular}{|c|c|c|}
\hline \multicolumn{3}{|c|}{ Oil Samples for Analysis Schedule } \\
\hline Samples & Sample Mileage & Sample Volume (ml) \\
\hline 01 - Complete & 0 & 70 \\
\hline 02 - Partial & 5000 & 30 \\
\hline 03 - Partial & 30000 & 30 \\
\hline 04 - Partial & 45000 & 30 \\
\hline 05 - Complete & 60000 & 70 \\
\hline 06 - Partial & 75000 & 30 \\
\hline 07 - Partial & 90000 & 30 \\
\hline 08 - Partial & 105000 & 30 \\
\hline \multirow[t]{2}{*}{09 - Complete } & 125000 & 70 \\
\hline & Total Volume & 390 \\
\hline
\end{tabular}

Table 3. Oil sample for analysis volume schedule 


\begin{tabular}{|l|l|}
\hline \multicolumn{1}{|c|}{ Complete Analysis } & \multicolumn{1}{c|}{ Partial Analysis } \\
\hline Viscosity at $100^{\circ} \mathrm{C}$ & Viscosidade a $100^{\circ} \mathrm{C}$ \\
\hline Viscosity a $40^{\circ} \mathrm{C}$ & - \\
\hline $\mathrm{VI}($ Viscosity Index) & - \\
\hline $\mathrm{TAN}$ & - \\
\hline Metal Wear (Al, Cr, $\mathrm{Cu}, \mathrm{Fe}, \mathrm{Mo}$, & $\begin{array}{l}\text { Metal Wear (Al, Cr, Cu, Fe, Mo, } \\
\mathrm{Ni}, \mathrm{Pb}, \mathrm{Si} . . .)\end{array}$ \\
\hline Water (Karl Fisher) $\mathrm{Pb}, \mathrm{Si} . .)$. \\
\hline FTIR Oxidation, Nitration and & Water (Karl Fisher) \\
Sulphatation & - \\
\hline Aspect & Aspect \\
\hline Color & Color \\
\hline Smell & Smell \\
\hline
\end{tabular}

Table 4. Oil analysis according to ASTM D445, D95 and D91 Standards

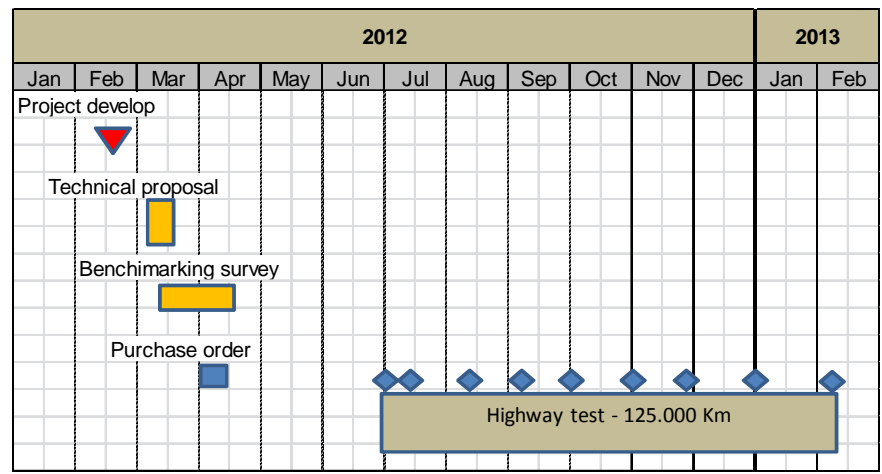

Picture 3. Project and test schedule

The oil analysis results show a stability trend for all metallic and non-metallic materials and also viscosity. The excess of Cupper $(\mathrm{Cu})$ in $75.000 \mathrm{Km}$ makes the oil replacement but after that the volume of $\mathrm{Cu}$ in PPM continuous high.

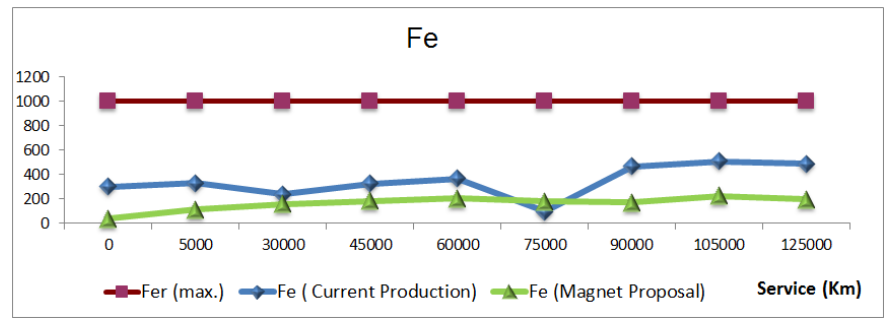

Graphic 1. Oil analysis show Fe stability trend

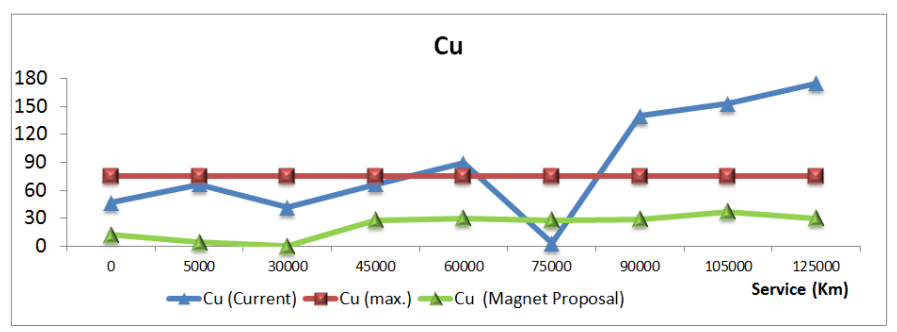

Graphic 2. Oil analysis show Cu stability trend 


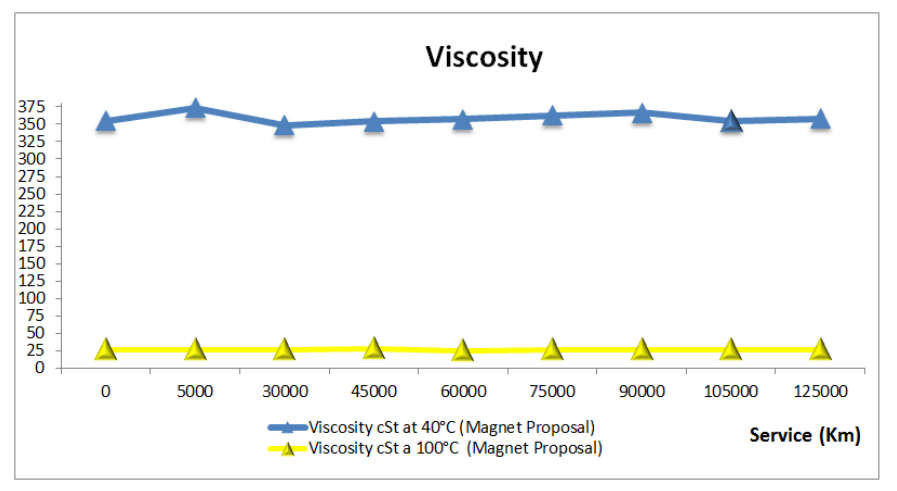

Graphic 3. Oil analysis show Viscosity stability trend

After durability test done was decided to replace the third axle and send to supplier to do a tear down. In parallel new third axle was assembled and keep running more $100.000 \mathrm{~km}$ at same durability test condition to evaluate the oil stability and also the possibility to change the oil change interval according to the data.

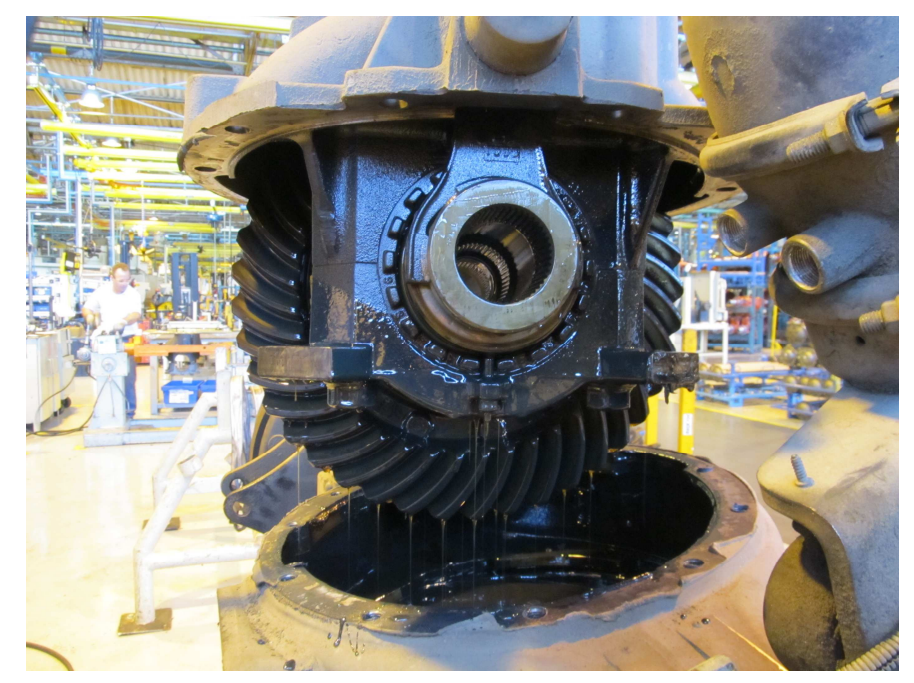

Picture 4. Differential disassembly

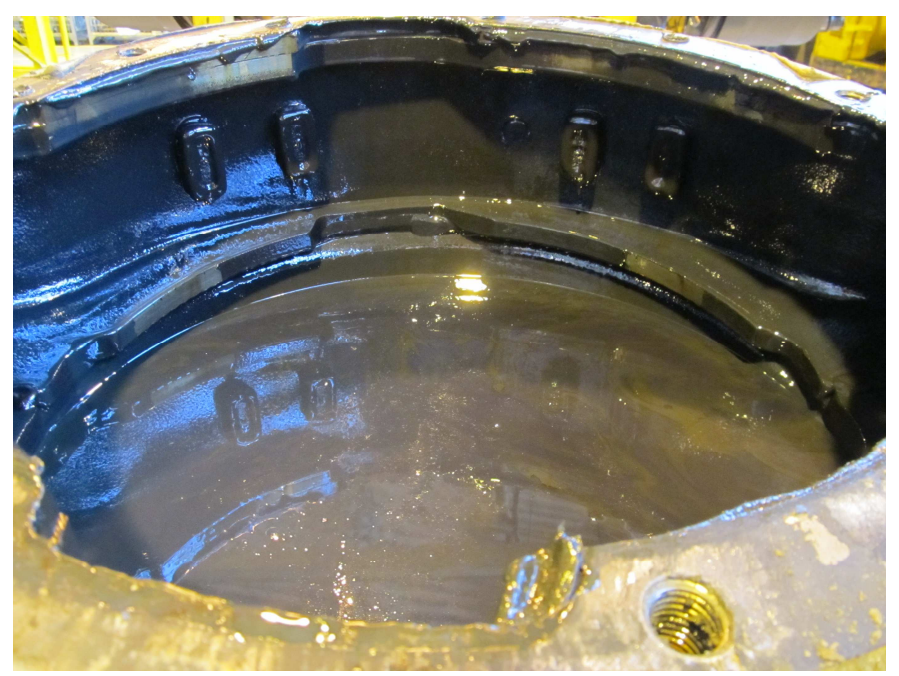

Picture 5. Magnets at rear axle housing 


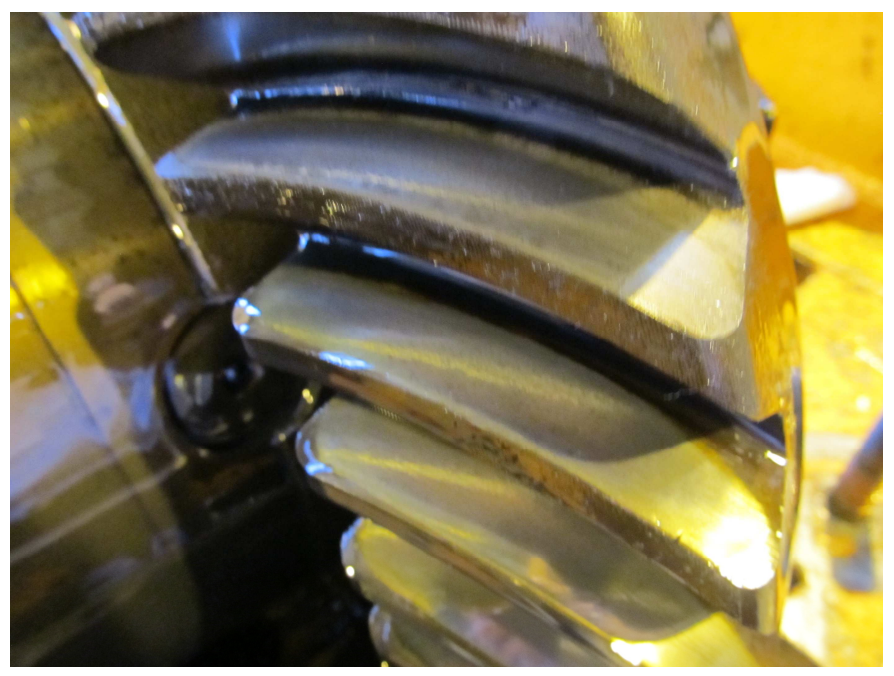

Picture 6. Ring Gear without pitting or damages

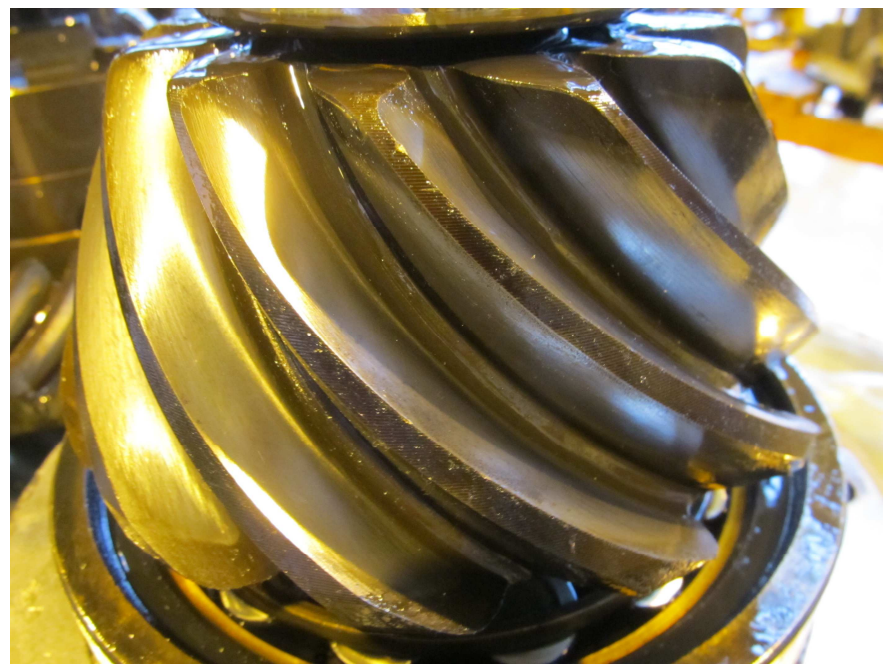

Picture 7. Pinion Gear without pitting or damages

The gear assy evaluation regarding wear and carbon case reduction, retainers condition, bearings life prediction is on going at rear axle maker and the results are previewed to calendar week 26.

\section{INCREASE THE OIL CHANGE INTERVAL POSSIBILITY}

Following the results found out at durability test were defined new test schedule with same truck at same highway test condition increase $100.000 \mathrm{~km}$ at first test. The current oil change interval for this application is $120.000 \mathrm{~km}$ considering first replacement oil. The proposal keep the same oil refuel only the necessary volume specified by rear axle maker. 


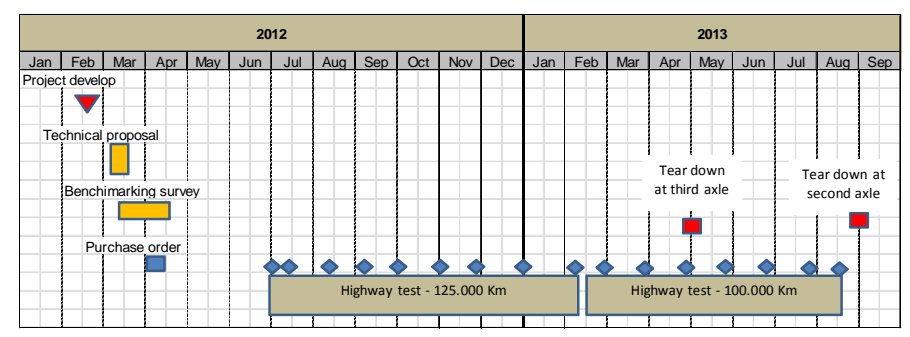

Picture 8. Test schedule with $100000 \mathrm{~km}$ increased

\begin{tabular}{|c|c|c|}
\hline \multicolumn{3}{|c|}{ Oil Samples for Analysis Schedule } \\
\hline Samples & Sample Mileage & Sample Volume (ml) \\
\hline 01 - Complete & 140000 & 70 \\
\hline 02 - Partial & 155000 & 30 \\
\hline 03 - Partial & 170000 & 30 \\
\hline 04 - Complete & 185000 & 70 \\
\hline 05 - Partial & 200000 & 30 \\
\hline 06 - Partial & 215000 & 30 \\
\hline 07 - Complete & 225000 & 70 \\
\hline & Total Volume & 330 \\
\hline
\end{tabular}

Table 5. Oil sample for analysis volume schedule

The oil analysis keep same trend up to now according to the graphic 4.

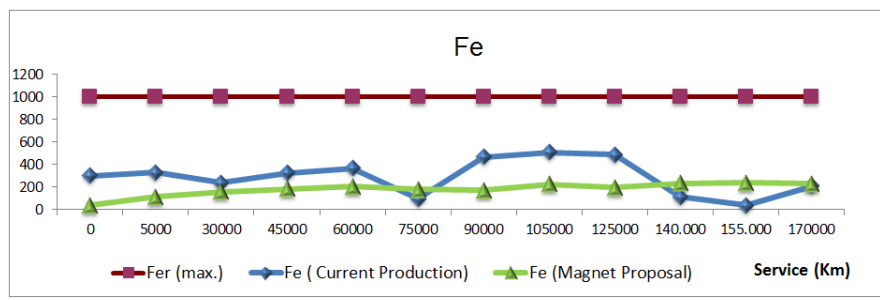

Graphic 4. Oil analysis show Fe stability trend until 170000km tested

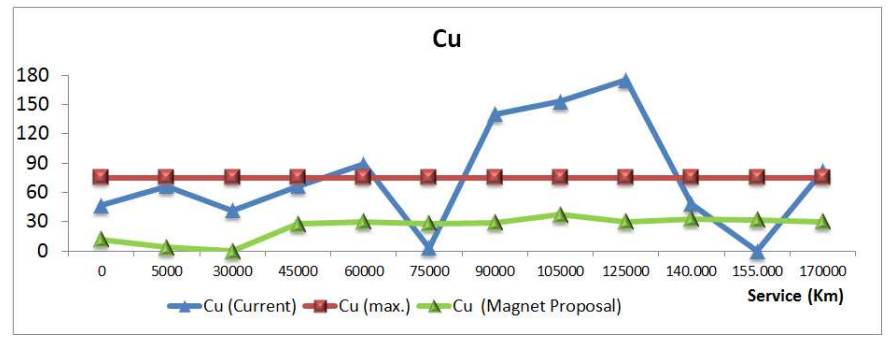

Graphic 5. Oil analysis show Cu stability trend until 170000km tested

The grahic 5 show new oil replacement at $155.000 \mathrm{~km}$. The $\mathrm{Cu}$ particles reduction at $140.000 \mathrm{~km}$ as a result of oil refueled to the level specified by rear axle maker. 


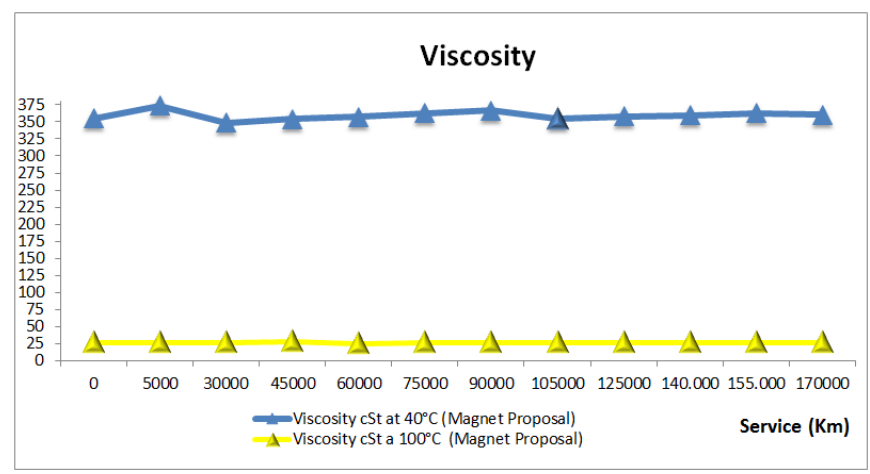

Graphic 6. Oil analysis show Viscosity stability trend until $170000 \mathrm{~km}$ tested

\section{CONCLUSIONS}

- Comparing the current rear axle and the proposal with magnet we could see clearly the stability trend at metallic and non-metallic particles.

- The teardown at rear axle and differential confirm by visual analysis that no pitting or damages were found out at ring gears, pinion gears, others components and the magnets were fixed properly according to the expectation.

- According to the analysis results, the first replacement oil can be avoided applying magnets at rear axle housing, reducing the hand work cost paid by Truck and Busses makers and also reduce the oil cost paid by customer.

- The oil change intervals are under analysis however it is possible to see the stability of materials and viscosity. All analysis shows no water presence avoiding oxidation possibility. Final analysis from rear axle maker will be available on calendar week 26, however we could see normal condition considering $50.000 \mathrm{~km}$ over then oil change specification.

\section{REFERENCES}

[1] W.D. Callister, Jr; Materials Sciences and Engineering, $7^{\text {th }}$ edition; 2007

[2] de Biasi, Ronaldo Sergio Ph.D. Class workbook - Material Science. IME INSTITUTO MILITAR DE ENGENHARIA.

[3] CONAMA Resolution 362 - Jun 23th 2005.

[4] Meritor do Brasil - Rear Axle Maintenance Course.

[5] Chevron do Brasl - Automotive Lubricants Pratice.

[6] Truck and Busses Maintenance Manual - Internet Truck and Busses Makers sites. 
[7] Fuel National Department (DNC); Resolution 729/90.

Halliday, David \& Resnik, Robert; Physic Foundation 3 - Electromagnetism $8^{\text {th }}$ Edition, 2011. 